\title{
El difícil regreso. Bashing, entre el honor y la supervivencia
}

\author{
A hard return. Bashing, between honor and survival
}

María Elena Romero ${ }^{1}$

\section{Resumen}

El cine es un difusor de ideas, costumbres y valores, es expresión de realidades ajenas. En momentos, controvertido por ofrecer temas que cuestionan el statu quo de la sociedad, permite un acercamiento a culturas lejanas a la propia. En este sentido, la cinematografía japonesa se ha caracterizado por mostrar un ambiente de éxito, una sociedad resiliente y con escenarios que dan muestra de un país boyante. Pero, también está el cine que se acerca más al Japón permeado por profundas diferencias, por valores que lastiman y provocan dilemas en la vida. Aquí, a través de la mirada de Masahiro Kobayashi y su obra Bashing revisamos la realidad que ofrece Japón a quienes, en su contexto de ideas y valores no cumplen con su deber y deshonran a su grupo. El bullying, la marginación y la humillación serán una constante en la obra revisada, ofreciendo una cara diferente de Japón, con escenarios sencillos, abrumadores y personas con profundos sentimientos. Así, consideramos que el cine japonés actual ofrece la oportunidad de mirar de cerca a ese complejo y apasionante país.

Palabras clave: Japón, cine, guerra, marginación, bullying

\section{Abstract}

Cinema spreads ideas, customs and values, it is an expression of other people's realities. At times, controversial for offering issues that question the status quo of society, although, it allows an approach to foreign cultures. In this sense, Japanese

Recibido: 06 de noviembre de 2019 Aceptado: 15 de diciembre de 2019 Publicado: 20 de diciembre de 2019

${ }^{1}$ Es Doctora en Ciencias Sociales con énfasis en Relaciones Internacionales por la Universidad Nacional Autónoma de México. Desde 1992 es Profesora Investigadora de la Facultad de Ciencias Políticas y Sociales de la Universidad de Colima (UCOL), estado de Colima, México. Su línea de investigación versa sobre temas de cooperación internacional para el desarrollo y Japón, sociedad y política de cooperación. Correo electrónico: meromero@ucol.mx. 
cinematography has been characterized by showing a successful environment, a resilient society and with scenarios that mirror a buoyant country. But, there is also another cinema, a controversial one, closer to the real Japan. Herein, through the gaze of Masahiro Kobayashi and his movie Bashing, we review the reality that Japan offers to those who, in their context of ideas and values, do not fulfill their duty and dishonor their group. Bullying, marginalization and humiliation will be a constant in the revised work, offering a different face of Japan, with simple, overwhelming scenarios and people with deep feelings. Thus, we consider that the current Japanese cinema offers the opportunity to look closely at this complex and exciting country.

Keywords: Japan, cinema, war, marginalization, bullying

\section{Introducción}

El cine, vehículo de acercamiento a la cultura ha sido analizado desde diversas perspectivas. Ya desde 1916 Ferdinand Saussure en su obra "Curso de Lingüística General" desde la semiótica advierte de la existencia de un contenido en el cine conformado por el significante o imagen y el significado o concepto que advierte son indisociables; el primero refleja una serie de elementos de los escrito, del sonido y del discurso, sustancia de la expresión; mientras que el segundo, significado es el concepto mismo. En este sentido, la filmografía contenedora y difusora de ideas, música, imágenes, costumbres y valores emerge como herramienta de expresión de realidades que calladas. Cine controvertido por tratar temas que cuestionan el statu quo de la sociedad; los directores de cine que se atreven a retratar estas realidades son cuestionados, a veces acallados y a menudo limitados en la realización y difusión de sus filmes. No obstante, el quehacer cinematográfico de osados directores provee un medio para el acercamiento a temas difíciles, dolorosos de experiencias históricas y culturales de los países.

La cinematografía japonesa ha estado polarizada, mientras que una mirada ofrece un panorama de éxito, honor, fuerza, resiliencia, pacifismo; otra se adentra en los recovecos de una cultura de profundas diferencias, marginación y humillación. Por ejemplo, el cine de guerra en Japón está inclinado a manifestar una posición de víctima y heroicidad; el cine del reconocido director Akira Kurosawa muestra ambas facetas, por un lado, al iniciar su carrera en el estudio de cine Toho y después de su primer película, La Leyenda del Gran Judo, sus trabajos fueron supervisados por el gobierno japonés y sus temas se enmarcaron en resaltar el nacionalismo japonés; no obstante, en su trabajo 
de la posguerra Kurosawa se muestra como un director crítico del régimen japonés y de su desempeño, permitiendo a través de su filmografía conocer dos momentos de la historia japonesa. Más recientemente, la producción de directores como Hayao Miyazaki trabajan con una narrativa que nos ubica en un Japón bidimensional, la realidad y la fantasía juegan para crear escenarios que reflejan la dicotomía de profundos sentimientos como, tristeza y alegría, soledad y amistad, esperanza y desolación.

En este orden de ideas, escribir sobre el cine japonés que retrata su sociedad y su cultura es una tarea compleja, es ser sensible a la otredad de lejano oriente y hacer a un lado los estereotipos occidentales que a menudo se erigen como valores universales. "Es sin embargo imposible lidiar con los filmes japoneses, de hecho con cualquier aspecto de la sociedad japonesa sin referencia constante a casi todos su otros aspectos" (Burch, 1979), es por tanto, necesario un acercamiento previo a Japón, su historia y sus costumbres.

Así, aquí se propone hacer una revisión de temas como la marginación y las diferencias sociales en Japón a través de la mirada de Kobayashi Masahiro y su obra Bashing, filme de 2005, premiada en ese año en el Festival de Cannes.

El breve trabajo se divide en tres apartados, el primeo plantea algunas aproximaciones al análisis de la filmografía japonesa y sus complejidades, el segundo, realiza una revisión de la película Bashing, sus intrincados personajes para recuperar los elementos claves que permiten entender cómo las diferencias sociales, de género, de rango y de relación padre - hija afectan la vida en el Japón de hoy. Finalmente, se plantean algunas ideas a manera de conclusión.

\section{Acercándose al cine japonés}

El cine es la tecnología más sofisticada y la forma narrativa completa de ficción estética y un profundo medio de inculcarnos un orden simbólico más amplio, en la medida que los personajes conducen sus vidas, las películas nos dicen, a nosotros, protagonistas de nuestras propias vidas, cómo conducirnos en la vida diaria en el marco de un sistema de ideas y valores (Ali Fuat, 2005, p. 5), un filme, por tanto, es un medio de acercamiento a la cultura, a la ideología, y costumbres de una sociedad, pero también es un instrumento que encierra una función ideológica, mucho depende de los fines y contextos de los directores. No obstante, el cine acerca e introduce a los otros a nuestras realidades, cuestiona valores y decisiones, replantea la historia a partir de la otredad. 
La noción de los otros deberá, entonces, entenderse en el contexto que distingue grupos, individuos, identifica realidades, normas, comunidades. Marca las distancia, tanto en el sentido geográfico como en el sentido socio-cultural. El cine tiene la capacidad de configurar entendimientos prevalecientes de la gente y sus espacios.

En sentido estricto, es el director, dentro del filme quien imprime el sentido esencial a la obra, a partir de la creatividad de grabar la realidad decidiendo la estructura de los cortes, escenas, formas de comunicación, enlaces, discursos y gestos que, aunados al buen manejo de la cámara, imprimen la fuerza y sentido de proyección de las ideas en el filme. En este sentido, es relevante el conocimiento de la filmografía del director, del contexto histórico que rodea la trama, del manejo de las ideas y cómo éstas se proyectan a fin de evitar el uso de metáforas que trivializan la cultura. Por ejemplo, en Japón, encontramos a menudo ideas tales como: los japoneses están limitados por sus procesos de pensamiento en su idioma, muy diferente a cualquier otro; no les gusta conocer a los recién llegados; representan a su grupo y por lo tanto, no pueden pronunciarse sobre ningún asunto sin consulta; los occidentales son individuos, pero los japoneses representan a un grupo que a su vez representa a Japón; los japoneses siempre son amables (Lewis, 1998 p.262).

Así, revisar y apreciar el cine japonés requiere del conocimiento de la sociedad y la cultura japonesa, en consecuencia, las escenas se concatenen para plantear una trama en un escenario definido por su historia, cada momento de la película ofrece un momento dado en Japón y el contexto social/cultural del cual emergen. La década de los años sesenta dio a luz a una nueva ola en el cine japonés, convirtiéndose en uno de los más potenciales y expresivos. "La experimentación formal floreció, como lo hizo su famoso precursor (Nagisa Oshima), especialmente en un contexto de sensibilidad a los poderes de la película para posicionar al espectador ideológicamente" (Casebier, 2016).

Oshima fue el líder de este movimiento, su película Shonen (Boy/niño) de 1969, Feliz Navidad Mr. Lawrence de 1983 o el Imperio de los Sentidos de 1976 han retratado crudamente a la sociedad japonesa, constituyéndose sus obras en ataques a los profundos fundamentos del sistema familiar japonés y representando una fuerte llamada a derribar las prácticas y valores tradicionales.

Más recientemente directores como Hirokazu Koreeda exploran temas sobre cómo asumir la muerte o sobre las relaciones familiares. Filmes como De tal padre, tal hijo o Nadie Sabe, muestran un Japón de valores que deben ser comprendidos en el contexto mismo de Japón para evitar, como diría Lewis (1998) percepciones erróneas. De igual forma, Yojiro Takita, con películas como Okuribito (El que despide) de 2008 muestran un Japón en donde las diferencias son marcadas por cosas tan cotidianas como 
el oficio que se desempeña ${ }^{2}$. De manera que el cine japonés ofrece en sus directores más críticos un retrato de una sociedad permeada por valores y prejuicios que de no ser entendidos en su contexto, generan imágenes erróneas de un país resiliente y capaz de sobreponerse a desastres generados por el hombre o por la naturaleza.

\section{¡Qué difícil regresar!}

Masahiro Kobayashi, controvertido y crítico director de cine japonés, refleja en sus obras realidades del comportamiento humano en Japón, de esa lucha entre el deber, el sentir y el hacer. Nacido en 1954; dirigió su primer filme en 1996 y en 1997 ganó el Gran Premio Yubari del Festival Internacional de Cine Fantástico. En sus inicios también se hizo acreedor por tres ocasiones al premio Cannes. En palabras del mismo director, la industria del cine en Japón ha decaído, pareciera que hoy se limitan al cine de gánsteres, a la explotación sexual o a los filmes "pinku", dice, no hay trabajos que valgan la pena. El cine japonés de su época no influyó en sus comienzos; aun las epopeyas de Kurosawa las consideró clasistas, cuando joven, no reconoció a los llamados maestros de la época; incluso se refiere a Nagisa Oshima como un simple director de estudio (Entrevista, 2010). Crítico también de la filmografía americana a la que se refiere como pionera del rodaje y la cámara móvil, pero elaborada con personas de escasa educación.

Dice de la nouvelle vague japonesa que fue solo un pretexto para llevar la política el cine, la gente con cierta preparación no lo vio, convirtiéndose solo en un tema de conversación; a diferencia de la nueva ola francesa que involucró a gente común y corriente, la japonesa no lo hizo "no estuve interesado en esos filmes, fui a verlos y me quede dormido" (Entrevista, 2010).

El estilo de Kobayashi lo hace especial, particularmente en los temas que trata y la forma de abordarlos. Financiando sus propios filmes para mantener su formato, Kobayashi define su trabajo como independiente, no atado a presupuestos y con un espíritu japonés que cuentan historias japonesas en japonés (Entrevista, 2010). Su forma única de plasmar relaciones familiares, sociales, entre individuos se distingue por la perseverancia de los personajes en mantener una relación; el permanente esfuerzo de los

\footnotetext{
${ }^{2}$ Burakumin, refiere a los grupos discriminados por sus oficios, no por motivos de raza ni lengua sino por desempeñar labores que desde el Japón feudal se consideraban impuros. La mayoría de ellos trabajaban en oficios relacionados con la muerte, como enterradores, curtidores de pieles, embalsamadores; la impureza se aplica en la religión sintoísta a quienes se relacionan con oficios vinculados a cadáveres o sangre.
} 
individuos por comunicarse a pesar de que no encuentren el ambiente propicio o que se enfrenten al rechazo. Bashing, una obra excepcional, refleja esta situación, se realiza con este objetivo en mente, muestra los sentimientos de los personajes principales, pero también deja ver el sentir de quienes están del otro lado. Película que nos enfrenta a los efectos de la guerra, a personajes solitarios, marginados, al honor, al compromiso, la lealtad y las relaciones padre - hija. Los sentimientos se mezclan y la perspectiva de la película se refleja en la mirada de los personajes imbuidos en su ambiente, sentimientos encontrados y compromisos; no es sólo la joven que se reencuentra con su comunidad después de sufrir los avatares de la guerra, están los otros, los que se quedaron ahí, que no vivieron una guerra, para los que el honor descansa en la muerte antes de la deshonra que representa el privilegio de seguir vivos.

Bashing (バッシング Basshingu) es la película laureada de Masahiro Kobayashi, premiada en Festival de Cannes en 2005 y nominada a La Palma de Oro y ganadora del gran premio del Tokyo FILMex. El argumento se centra en Yuko Takai, quien junto a otros activistas políticos japoneses en Medio Oriente son capturados y tomados como rehenes; mientras los compañeros de Yoko mueren, ella logra volver a casa, en donde enfrentara un ambiente de repudio por no cumplir con su misión y con su deber, ¿por qué no suicidarse para mostrar el valor y la fortaleza del pueblo japonés?

Yuko, interpretada por Fusaku Urabe, es una joven japonesa voluntaria durante la Guerra de Irak (aunque el filme tiene su argumento en los hechos reales de las fuerzas de autodefensa que participaron en la Guerra de Irak, no se hace ninguna referencia a ésta). ${ }^{3}$ Yuko, junto con otros activistas fue secuestrada, al pasar de los años, sus compañeros mueren, pero ella logra ser librada y volver a casa. El reencuentro con su país no será fácil. La guerra con todas sus pérdidas trastoca los sentidos y las emociones. Las intersubjetividades de quienes conviven en la guerra cambia los sentidos, los nervios se tensan y el instinto de supervivencia hace que quienes viven el desastre no se quiebren. Vivir se convierte en el objetivo fundamental, representando un triunfo el salir vivo de la contienda. No para Yuko, no para quienes le rodean.

\footnotetext{
${ }^{3}$ Esta guerra es un hito en la historia de Japón ya que representa la primera incursión de militares japoneses en una zona bélica después de la segunda Guerra Mundial. Un convoy de 25 vehículos, con 50 militares japoneses a bordo, atraviesan a principios de 2004 la frontera entre Irak y Kuwait. La arenga de Yasushi Kiyota, coronel a cargo de la unidad, es determinante: "Hagamos el trabajo que hace historia, Hagamos nuestro trabajo tal y como debemos hacerlo" (El País, 2004). Las unidades japonesas tendrás básicamente una misión humanitaria, de acuerdo al Artículo 9 constitucional japonés, las fuerzas de autodefensa solo podrán abrir fuego para defenderse.
} 
Bashing retrata el momento del regreso, la reincorporación a la cotidianidad, a la comunidad. Yuko enfrentará un enorme sentimiento de rechazo de la sociedad que le rodea. Para su comunidad no será fácil entender por qué ayudar a los extraños en lugar de contribuir al trabajo en su propio país, considerando esto un acto despreciable y de vergüenza, pero más controvertido aun, volver viva, no haber muerto con honor será objeto de un mayor rechazo.

Kobayashi retrata diversas situaciones a lo largo de la película que muestran un rechazo tangible hacia Yuko, quien es continuamente hostigada, haciéndole sentir que morir es preferible a vivir sin honor. En la película la frase expresada por el novio de Yuko traduce esta compleja moralidad: "iy se te ocurrió regresar! ¡qué vergüenza!, si hubieses muerto serías hoy una heroína”. Las acciones de hostigamiento alcanzan a su familia. El padre de Yuko, en una situación verdaderamente humillante, deberá suplicar de rodillas no ser despedido de su trabajo, solamente por haber aceptado de regreso a Yuko en casa, su mismo jefe le dice: "la consientes mucho, esas son las consecuencias".

Bashing nos deja ver el sentido de la vida y la muerte, mejor siempre una muerte con honor que no solo comprende al individuo si no al mismo grupo al que pertenece. Yuko representa el honor del pueblo japonés. El Coronel a cargo de la unidad que incursiona en Irak en 2004 dejó claro el sentido de responsabilidad de quienes participaban y la importancia no sólo para el orgullo de ellos, sino para todo el pueblo japonés, "Hagamos el trabajo que hace historia, hagamos nuestro trabajo tal y como debemos hacerlo" (El País, 2004) Un grupo escribe la historia del país y el deber del mismo para cumplir con honor.

Al regresar a Japón, Yuko es maltratada básicamente por "agitar el agua"; en otras palabras, por no suicidarse y por hacer que los japoneses parezcan débiles. ${ }^{4}$

La riqueza de la película además, nos muestra otro aspecto de la cultura de relaciones sociales en Japón, el discurso con un trasfondo, un discurso no directo, la capacidad del japonés de entender lo que está sin que requiera una explicación directa; el jefe de la empresa en donde trabaja el papá de Yuko jamás lo despedirá directamente y menos le dejará ver el motivo, la aceptación del regreso de su hija con deshonor que cubre a todos aquellos que tienen un vínculo directo o indirecto con ella. El director de la empresa solo insinuará la necesidad de que el padre renuncie para evitar un mayor

\footnotetext{
${ }^{4}$ Esta historia se basa en los asuntos reales del secuestro de tres activistas políticos japoneses por terroristas musulmanes en Irak en abril de 2004. Yuko Takai es el reflejo de Nahoko Takato, un activista político, que también fue duramente criticado por casi todos los japoneses (Ver la Story line del filme en IMDb, 2006).
} 
rechazo. La situación muestra como la sociedad japonesa evita la confrontación directa, las insinuaciones, las metáforas, las sugerencias, serán preferibles a expresar una opinión o sentimiento directo. De manera que Bashing nos acerca de forma sutil pero concisa a la cultura social y cotidiana de Japón, al valor del honor y el compromiso con el grupo al que se pertenece y representa. A un país de jerarquías, marginación y disculpas públicas.

La dirección y la cámara en Bashing resaltan las expresiones de los personajes, quienes en una mirada, en una posición corporal o en una sonrisa reflejan la complejidad de los sentimientos en momentos claves de la película; mirar el miedo que Yuko en sus ojos al entrar a una tienda a comprar su comida, se vuelve inentendible después de haber vivido los horrores de la guerra y de un secuestro, el miedo de no ser aceptada, de no pertenecer es mayor al que representa la muerte en el cumplimiento de su misión.

En otro momento, el júbilo y desesperanza se entremezclan en el reencuentro de Yuko con su novio; la alegría de pensarlo, del recorrido en bicicleta para encontrarlo y la frustración de no encontrar una bienvenida, la tristeza y desencanto ante la cruda respuesta del muchacho no será necesario plasmarlo en diálogos, los gestos dibujados en el rostro de la protagonista hablarán por sí solos. Asimismo, la postura corporal de Ryuzo Tanaka, actor que interpreta el padre de Yuko, de rodillas, humillado o meditabundo a la orilla del mar refleja en su actitud el conflicto que vive un padre japonés al verse en el dilema del deber ser en la sociedad japonesa y el lazo paternal que lo une a Yuko, aunado al deseo reprimido de expresar la felicidad de ver a su hija viva.

El acoso, la agresión, el bullying y la marginación están presentes en la sociedad japonesa, tratando siempre de dejar de lado y desaparecer aquello que es diferente, que genera un sentimiento de humillación y pérdida. Las presiones sociales por el orden jerárquico han sido consideradas en Japón relativamente más fuertes que en otras naciones, ya sea por cuestiones culturales o institucionales. Japón es un caso que permite entender los aspectos sociológicos del rechazo y el acoso. Como lo retrata Kobayashi en el filme, la posibilidad de ser objeto de bullying es una cuestión patológica que afecta el proceso de inserción o reinserción de personas que por diversas circunstancias dejan el país y que deben enfrentar una sociedad compuesta y orientada por grupos, jerárquicamente organizada y con fuertes vínculos de dominio y poder en las relaciones humanas; cada uno de los miembros del grupo desempeña una función y asume un compromiso con su país, con su familia, con sus compañeros de trabajo, la deshonra permea a todos. Cada uno de los miembros de ese grupo se inserta y es aceptado y éste a su vez acepta su posición. Parece, para algunos sociólogos que el bullying es la mejor forma de entender a la sociedad japonesa de hoy, porque es el mejor concepto para 
enmarcar las relaciones sociales en Japón tanto en la escuela, como en el trabajo y en la vida en sociedad, en donde el diferente no tiene cabida (Yoneyama, 2008).

Bashing crea así una atmosfera sencilla, lugares comunes, que permea toda la película, nos traslada a un ambiente deprimente y depresivo entre cielos grises, fábricas humeantes y un mar tranquilo en Hokkaido. Quizá, como expresó el mismo director, el escenario tenía que reflejar el sentir de Yuko, su propia existencia.

Bashing es un filme complejo, muestra los claroscuros de una sociedad, las batallas personales, familiares que se deben de enfrentar día a día. Es un ejemplo de perseverancia que expone asuntos controvertidos de la sociedad japonesa y lo lleva a uno de la depresión a la idea de saber que siempre habrá algo más; con la sonrisa dibujada en el rostro de Yuko al final de la trama, el director abre la puerta para una multiplicidad de interpretaciones de lo que puede traer una elección de vida. Kobayashi, así, permite acercarse a la cotidianidad japonesa, a sus valores y prejuicios, haciendo del cine un medio de inmersión en culturas equidistantes, un vehículo para transmitir ideas y valores, para aprender. Con un estilo muy personal y una estética minimalista, sin grandes escenas ni escenarios, el director marca la pauta para una nueva etapa del cine japonés.

\section{Comentarios finales}

El cine japonés de hoy que retrata su sociedad, su cultura, sus claroscuros es una tarea compleja, requiere de sensibilidad para aceptar la realidad de los otros, de ese lejano oriente que hoy la tecnología cinematográfica trae a nuestros entornos; permitiendo tomar distancia de los estereotipos construidos a partir de las realidades de directores no japoneses y advertir que existen otros valores, otra forma de enfrentar los cambios y asumirse como parte de la comunidad en la que se desenvuelve.

Bashing, filme de Masahiro Kobayashi permite, en el marco de escenarios comunes de Japón, acercarnos a la realidad de quienes se enfrentan a decisiones en vida que contradicen los cánones de convivencia de una comunidad. La muerte como la alternativa para evitar el deshonor cuestiona la capacidad de resistencia y el triunfo que para otros, representaría haber sobrevivido a la guerra. Revela el aislamiento en el que se sumergen quienes vuelven de la guerra, no es solo que los demás la discriminen, es la protagonista quien no encuentra un espacio y prefiere el ostracismo, es una obra que sin duda encierra una fuerte crítica a la intolerancia de una sociedad rígida, guiada por valores morales que solo son entendibles en su contexto histórico y cultural. 
De manera que el cine, así, funciona como un vehículo de acercamiento a otras realidades, a la otredad que no se entiende y acepta si no se tiene previo conocimiento de lo que representa ser japonés, pertenecer a un grupo, representarlo siempre y aceptar las normas de comportamiento

\section{Referencias}

Ali Fuat, Ş. (2005). Cinema and Representation in International Relations: Hollywood Cinema and the Cold War, M.O.: Middle East Technical University

Burch, N. (1979). To the distant observever. Form and meaning in the Japanese cinema. USA: University of California Press

Casebier, A. (2016) Japanese film and culture, College Course File con referencia en Journal of Film and Video, Vol. 39, No. 1, Japanese Cinema, invierno de 1987, pp. 52-64. EEE.UU: University of Illinois Press University Film \& Video Association Stable URL: http://www.jstor.org/stable/20687758

El País (2004). Tropas japonesas entran en Irak en su primera misión desde la II Guerra Mundial, reporte internacional, España. Disponible en https://elpais.com/internacional/2004/02/08/actualidad/1076194803_850215.html

Entrevista (2019). Entrevista conducida por Nicholas Vroman y Ken Shima en Tokio, diciembre de 2010. Traducción al inglés de Shizuko Masamori. Disponible en http://eigagogo.free.fr/en/interview-masahiro-kobayashi.php

IMDB (2006) Bashing, story line, disponible en https://www.imdb.com/title/tt0456836/

Lewis, Richard D. (1998). When Cultures Collide: Managing Sucessfully Across Cultures. Londres: Nicholas Brealey.

Yoneyama, Shoko (2008). The Era of Bullying: Japan Under Neoliberalism, en The AsiaPacific Journal, Vol. 1-3-09, December 31 